\title{
Cultural and molecular characterization of tetracycline resistant microflora associated with dental caries
}

\author{
Luhana K.K. and Patel H.D. \\ ${ }^{1}$ Shree M. and N. Virani Science College, Rajkot, Gujarat, kuldeep_luhana@yahoo.co.in \\ ${ }^{2}$ Disha life Sciences Pvt. Ltd, 301, Trade Center, Gurukul Road, Ahemedabad, hp3948@gmail.com
}

\begin{abstract}
Dental caries is the most common chronic disease. Tetracycline is commonly used in dental practice as a prophylactic agent and for treatment of oral infections. The wide use of tetracycline had resulted in a major increase in the rate of tetracycline resistance among bacteria. Substantial epidemiologic evidence links Streptococcus mutans to caries; the pathobiology of caries may involve more complex communities of bacterial species. Molecular methods for bacterial identification and enumeration now make it possible to more precisely study the micro biota associated with dental caries. The purpose of this study was to characterize the tetracycline resistant microorganism associated with the dental caries using cultural \& molecular method. The first step involved 20 samples from patients with different level of dental caries. From which 33 different isolates were obtained, out of which 12 showed resistances to tetracycline and 5 were having maximum MIC indicating that they are highly resistant. These resistant microorganisms were identified to the species level by growing them on a suitable medium using the antibiotic tetracycline and were analyzed with the help of FAME analysis, which indicated that different strains of the Pseudomonas aeruginosa and Bacillus subtilis were present. The second step involved identifying the tet $\mathrm{k}$ gene in the cultures. Tet $\mathrm{k}$ was amplified under standard conditions by using specific primers results. Interestingly, the results showed that tet $\mathrm{k}$ gene was present in all the sample. Tet $\mathrm{k}$ gene is involved in imparting the resistant to the tetracycline by acting as a efflux pump. RFLP analyses were used in order to identify the polymorphic forms of the tet $k$. The Hindlll digest suggest that high resistance to tetracycline was acquired due to some mutations in the genome.
\end{abstract}

Keywords: Dental caries, tet K gene, Bacteria, FAME analysis, Tetracycline, PCR, RFLP

\section{Introduction}

Dental caries is a disease in which oral micro flora damage the hard tooth (enamel, dentin, cementum) by some metabolic processes. These damaged tissues progressively break down creating holes in teeth. Today, caries remains one of the most common diseases throughout the world. Specific type of acid producing bacteria cause tooth decay in presence of some fermentable carbohydrates (glucose, sucrose, fructose). The mouth contains a wide variety of oral bacteria, but only a few specific species of bacteria are believed to cause dental caries: Streptococcus mutants and Lactobacilli. Among them Lactobacillus acidophilus, Actinomyces viscosus, Nocardia spp., and Streptococcus mutants are most closely associated with caries, particularly root caries. Bacteria collect around the teeth and gums in a sticky, creamy-colored mass called plaque, which forms a biofilm. Some sites collect plaque more commonly than others. The grooves on the biting surfaces of molar and premolar teeth provide microscopic retention, as does the point of contact between teeth. In developed countries number of the cases now lowering down but in developing countries it is being a serious problem regarding dental health. Antibiotics are used to treat such dental caries. Antibiotics kill the bacteria mainly by inhibiting their protein synthesis machinery \& pathway using several different mechanisms. Sometimes bacteria evolve some resistance mechanisms against antibiotics. Due to chemotherapy against some infectious diseases some pathogenic microbes are evolving different antibiotic resistance strains. This is going to be serious problem regarding human health \& environment.

\section{Material and Methods Subject selection \\ The subjects were selected from different dental clinics in Ahmedabad city. The patients were suffering from different stages of dental caries. They belonged to different age groups ranging from 20 years to 60 years. All the subjects were selected randomly. Total 20 subjects were selected to collect the samples.}

\section{Sample collection}

Saliva, extracted tooth or surrounding tissue samples were obtained from the patients. Samples were collected in $5 \mathrm{~mL}$ of sterile $\mathrm{N}$ saline tubes sealed with tube caps. The samples were collected by taking medical precautions. Pooled plaque from the caries subjects was collected separately from four types of sites: (i) surfaces of intact enamel, (ii) surfaces of white spot lesions, (iii) surfaces of cavitated lesions, and (iv) Excavated carious dentin from cavitated lesions. For the enamel, white spot lesions, and cavitated lesions, the plaque was obtained by swiping the tooth surface with a dental explorer and wiping the plaque onto a coarse endodontic paper point. The carious dentin was excavated either with a spoon excavator. The samples were then transferred to the laboratory for further study. 
Isolation of bacteria:

The samples were subjected for serial 10 -fold dilution. Each sample was plated on nutrient agar plates and incubated at $37^{\circ} \mathrm{C}$ so that to separate the different colonies. The isolates were enumerated according to their morphological characteristics. One representative colony of each type was sub cultured for further selection and studies. The isolated colonies were then grown on the nutrient agar plates containing 8-16 $\mu \mathrm{g} / \mathrm{mL}$ tetracycline, as well as antibiotic free media plates as controls. The resistant colonies were selected for further studies. These colonies were preserved in $\mathrm{N}$-agar slants at low temperature.

\section{Identification of organism}

Differential staining (Gram's staining) was performed for identification of isolated bacterial cultures. Gram's staining was performed to differentiate the bacteria in two major groups called gram's positive and gram's negative. This was done on the basis of their cell wall composition. For identification of organisms FAME analysis was performed using SHERLOCK MIDI system.

\section{FAME Analysis}

Four reagents are required to cleave the fatty acids from lipids: Reagent 1, Saponification- $45 \mathrm{~g}$ sodium hydroxide, $150 \mathrm{ml}$ methanol, and $150 \mathrm{ml}$ distilled water. Reagent 2, Methylation- $325 \mathrm{ml}$ $6.0 \mathrm{~N}$ hydrochloric acid and $275 \mathrm{ml}$ methyl alcohol. Reagent 3, Extraction- $200 \mathrm{ml}$ hexane and $200 \mathrm{ml}$ methyl tert-butyl ether. Reagent 4, Sample Cleanup-10.8 g sodium hydroxide dissolved in $900 \mathrm{ml}$ distilled water. The five steps to prepare GC ready extracts are illustrated in Figure 1. Harvesting- A $4 \mathrm{~mm}$ loop is used to harvest about $40 \mathrm{mg}$ of bacterial cells from the third quadrant (second or first quadrant if slow growing) of the quadrant streaked plate. The cells are placed in a clean $13 \times 100$ culture tube. Saponification- $1.0 \mathrm{ml}$ of Reagent 1 is added to each tube containing cells. The tubes are securely sealed with Teflon lined caps, vortexed briefly and heated in a boiling water bath for 5 minutes, at which time the tubes are vigorously vortexed for 5-10 seconds and returned to the water bath to complete the 30 minute heating. Methylation-The cooled tubes are uncapped, $2 \mathrm{ml}$ of Reagent 2 is added. The tubes are capped and briefly vortexed. After vortexing, the tubes are heated for $10 \pm 1$ minute at $80^{\circ} \pm 1^{\circ} \mathrm{C}$.

Extraction- Addition of $1.25 \mathrm{ml}$ of Reagent 3 to the cooled tubes is followed by recapping and gentle tumbling on a clinical rotator for about 10 minutes. The tubes are uncapped and the aqueous (lower) phase is pipetted out and discarded. Base Wash-About $3 \mathrm{ml}$ of Reagent 4 is added to the organic phase remaining in the tubes, the tubes are recapped, and tumbled for 5 minutes. Following uncapping, about $2 / 3$ of the organic phase is pipette into a GC vial which is capped and ready for analysis.

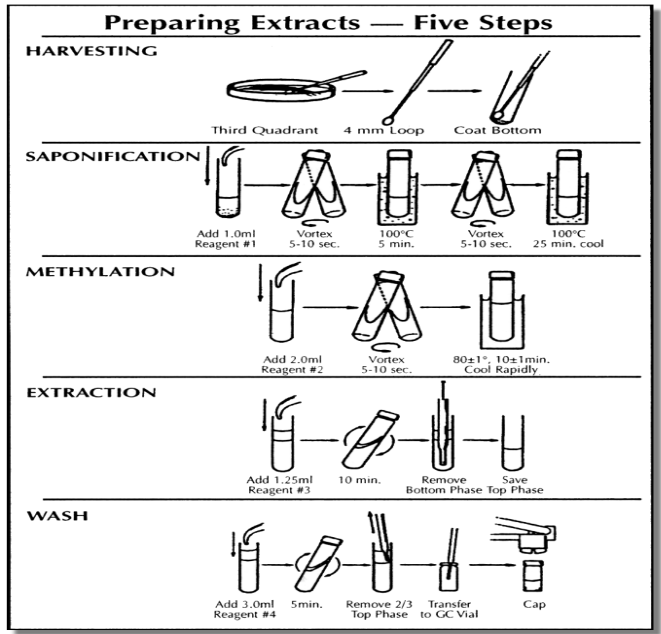

Fig. 1- Steps involved in FAME analysis.

\section{Isolation of antibiotic resistant bacteria} (Determination of MIC)

Previously isolated organisms are plated on the $\mathrm{N}$-agar media plates having tetracycline in the range of $8-16 \mu \mathrm{g} / \mathrm{ml}$ at the center of the plate in the cup. The zone of inhibition is checked. The organisms which can grow near the cup and do not show the zone of inhibition are resistant to that much concentration of that antibiotic. Next time the range of antibiotic concentration is narrowed to $14-16 \mu \mathrm{g} / \mathrm{ml}$. This is done for several times to find out exact maximum concentration of antibiotic which can be tolerated by the microorganism.

\section{Isolation of DNA}

The samples were inoculated in $5 \mathrm{ml}$ LB broth and incubated at $37^{\circ} \mathrm{C}$ for 24 hours. They were centrifuged at $8000 \mathrm{rpm}$ for $10 \mathrm{mins}$. The supernatant was discarded by taking care that the pellet should not be dislodged. Pellets were resuspended in $500 \mu \mathrm{L}$ of TE buffer. Incubate the samples at $-20^{\circ} \mathrm{C}$ for 1 hour. The samples were brought to room temperature and then incubated at $37^{\circ} \mathrm{C}$ for 1 hour. The cells were given lysis treatment by the adding $5 \mu \mathrm{L}$ proteinase $\mathrm{K}$ enzyme and $30 \mu \mathrm{L} 10 \% \mathrm{w} / \mathrm{v}$ SDS. The suspension was extracted with phenol: chloroform (1:1) in equal amount. This was centrifuged at $8000 \mathrm{rpm}$ for 10 minutes at $4^{\circ} \mathrm{C}$. The upper aqueous layer was carefully transferred to the new eppendroff tube. This was extracted again by adding equal volume of phenol: chloroform: isoamyl alcohol (25:24:1) and centrifuged at $8000 \mathrm{rpm}$ for 10 minutes at $4^{\circ} \mathrm{C}$. Again the upper aqueous phase was carefully transferred to the new vial. Double volume of 70 
$\%$ ethanol was added to the suspension along with 1/10th volume of $3 \mathrm{M}$ sodium acetate. This mixture was kept at $-20^{\circ} \mathrm{C}$ for 20 minutes. It was centrifuged at $8000 \mathrm{rpm}$ for $10 \mathrm{mins}$. Alcohol was discarded and the tube was allowed to air dry. Care was taken that the pellet should not be dislodged. Pellet was dissolved in $50 \mu \mathrm{L}$ of TE buffer. The quantitative and qualitative analysis of extracted DNA was done by measuring the absorbance at $260 \mathrm{~nm}$ and $280 \mathrm{~nm}$ and the ratio of A260/A280 was calculated. The DNA samples were electrophoresed on $0.8 \% \mathrm{w} / \mathrm{v}$ agarose gel. DNA is quantified in spectrophotometer. Absorbance was measured at 260 and $280 \mathrm{~nm}$.

\section{PCR of tetK gene}

PCR reaction were carried out in $12.5 \mu \mathrm{l}$ volumes in which $100 \mathrm{ng}$ of target DNA after standardization for best results was used. Amplifications were performed using the following reaction mixture: $0.3 \mu \mathrm{M}$ of primer, $200 \mu \mathrm{M}$ of dNTPs, 0.75 units of Taq DNA polymerase diluted appropriately with $10 \mathrm{X}$ assay buffer containing $15 \mathrm{Mm} \mathrm{MgCl}$. The primer used was 5'-TAA AGT AAT GGT ACC TGG TAA ATC AAC-3'. The temperature profile for all the reactions was $94^{\circ} \mathrm{C}$ for 5 minutes followed by 35 cycles of $94^{\circ} \mathrm{C}$ for 30 seconds, $55^{\circ} \mathrm{C}$ for $1 \mathrm{~min}$, $72^{\circ} \mathrm{C}$ for 1 minutes with final extension at $72^{\circ} \mathrm{C}$ for 5 minutes. Amplification products were maintained at $4^{\circ} \mathrm{C}$ until electrophoresis. The reaction products were analyzed by loading the total amplified product in $50 \mathrm{ml} 1 \% \mathrm{w} / \mathrm{v}$ agarose gels containing $5 \mu \mathrm{L}$ EtBr. Electrophoresis was performed at $100 \mathrm{~V}$ for approximately 1.5 hour.

\section{RFLP analysis}

For RFLP analysis of isolated DNA samples of identified organism the protocol was standardized. According to it $14 \mu \mathrm{L}$ nuclease free water, $2 \mu \mathrm{L} 10 \mathrm{X}$ assay buffer, $2 \mu \mathrm{L}$ DNA, $1 \mu \mathrm{L}$ restriction enzyme (HindIII) was mixed to make final reaction mixture of $19 \mu \mathrm{L}$. The mixture was incubated at $37^{\circ} \mathrm{C}$ for 1 hour. After incubation the digested DNA was mixed with $5 \mu \mathrm{L}$ of gel loading dye and then allowed to electrophorus to observe the restriction band pattern.

\section{Results}

Collection \& Isolation of sample

20 saliva and plaque samples were obtained from 20 patients having dental caries from several dental hospitals in Ahmedabad. From these more than 33 isolates were obtained were enumerated according to their morphologies, and one representative colony of each colony type was sub cultured.

Selection of tetracycline resistant organism: Out of the 33 isolates twelve were found to be resistant to tetracycline and used for further studies. Apart from these twelve cultures showing maximum resistant to tetracycline were used for further studies (Figure- 2).

Tetracycline susceptibility testing

The isolates were divided into two groups according to their tetracycline susceptibility. Group I which included all cultures having an MIC of tetracycline to be near about $16 \mu \mathrm{g} / \mathrm{ml}$ and Group II which had the cultures having an MIC to be between $11-12 \mu \mathrm{g} / \mathrm{ml}$ (Table-4).

\section{Characterization and Identification of isolated bacteria}

Colony characters for the isolates were examined (Table- 1). Based on staining procedures, 4 isolates were gram negative and 1 isolate was gram positive (Table- 2). The table enlists the identified species (Table- 3 ). All the isolates were identified by FAME analysis.

\section{Isolation of genomic DNA}

Isolated genomic DNA was quantified by measuring $O D$ at $260 \mathrm{~nm}$ and $280 \mathrm{~nm}$. The results are shown in table (Table- 5 ). The quality of DNA was examined on Agarose gel (Fig. - 3).

\section{Amplification of tet(k) gene}

Gene responsible for tetracycline resistance (tetK) was successfully amplified using gene specific primer. All the DNA samples showing amplification giving evidence that tetK gene is present in all the 5 tetracycline resistant organisms. The results are shown in figure (Fig.4).

\section{RFLP analysis}

The RFLP profile for the genomic DNA of all the five isolates giving the sign that the 4 organisms are not more diverse but it is showing a little variation in band pattern. So it is indicating that the organisms are having different place in phylogenetic tree and 1 is more diverse having very far place on tree. The results of RFLP are represented in figure (Fig. - 5).

\section{Construction of phylogenetic tree}

The phylogenetic tree was constructed using MIDI system software based on FAME analysis. Two isolates of Pseudomonas aeruginosa (sample- D9 \& D8) are closely related to each other while two other of the same species (sample- D15 \& D5) are closely similar but diversed from other two. One organism is Bacillus subtilis (sample- D16) and it is quite far from all other isolates. The phylogenetic tree is shown in figure (Fig.- 5).

\section{Conclusion}

All these resistant bacteria showed very high inhibitory concentrations ranging $14-16 \mu \mathrm{g} / \mathrm{mL}$, which is quite higher than the MIC of $11 \mu \mathrm{g} / \mathrm{mL}$ observed in previous studies. Out of the total number of organism the resistant organisms were 
limited only to certain species. The majority of these were $P$.aeroginosa consisting of $80 \%$ of the isolates. Range of the resistance was found to vary with in the isolates of a single species. The resistance phenotype was limited to the species of the organism. The organisms belonging to the $P$.aeroginosa have difference in their fatty acid profile as well as genetic profile. It is showing evidence for the mutations at some sites and so evolving some new strains of the organisms responsible for the dental caries \& resistant to tetracycline.

\section{Acknowledgement}

Special thanks to Dr. Sudha Sahay, Mrs. Sindhura Gudipati, Mr. D.P. Singh for their valuable guidance to Mr. Abhishek Bharati, Mr. Kundan Sharma, Mr. Akash Sahu, Mrs. Pragati Mishra, Ms. Krupa Desai, Mr. Adarsh Mujapara, Ms. Pooja Paun, Mr. Uday Thakker, Mr. Ashutosh Thakker, and for their constant support during this research work.

\section{References}

[1] Miranda C.D., Kehrenberg C., Ulep C., Schwarz S., Roberts M.C. (2003) Antimicrobial agents and chemotherapy; 47(3): 883-888.

[2] Guay G.G., Rothstein D.M. (1993) Antimicrobial agents and chemotherapy; 37(2): 191-198.

[3] Chopra I., Roberts M. (2001) Microbiology and molecular biology reviews; 65(2): 232-260.

[4] Schmitz F.J., Krey A., Sadurski R., Verhoef J., Milatovic D. (2001) Journal of antimicrobial chemotherapy; 47: 239246.

[5] Sweeney L.C., Dave J., Chambers P.A., Heritage J. (2003) Journal of Antimicrobial Chemotherapy; 53: 567576.

[6] Aas J.A., Griffen A.L., Dardis S.R., Lee A.M., Olsen L.I., Dewhirst F.E., Leys E.J., Paster B.J. (2008) Journal of Clinical Microbiology; 46(4): 1407-1417.

[7] Paster B.J., Boches S.K., Galvin J.L., Ericson R.E., Lau C.N., Levanos V.A., Sahasrabudhe A., Dewhirst F.E. (2001) Journal of bacteriology; 183(12): 37703783.

[8] Bowen W.H. (2002) Crit. Rev. Oral Biol. Med.; 13(2): 126-131.
[9] Li Y., Ge Y., Saxena D., Caufield P.W. (2007) Journal of clinical microbiology; 45(1): 81-87.

[10] Duncan M.J. (2003) Crit. Rev. Oral Biol. Med:; 14(3): 175-187.

[11] Chiu C.H. (2003) ISAAR: 59-60.

[12] Jacques N. (1998) Australian Dental journal; 43(2): 87-98.

[13] Babalola O.O. (2003) African journal of biotechnology; 2(12): 710-713.

[14] Kuramitsu H.K. (2003) Crit. Rev. Oral Biol. Med.; 14(5): 331-344.

[15] Becker M.R., Paster B.J., Leys E.J., Moeschberger M.L., Kenyon S.G., Galvin J.L., Boches S.K., Dewhirst F.E., Griffen A.L. (2002) Journal of clinical microbiology; 40(3): 1001-1009.

[16] Munson M.A., Banerjee A., Watson T.F., Wade W.G. (2004) Journal of clinical microbiology; 42(7): 3023-3029.

[17] Chhour K., Nadkarni M.A., Byun R., Martin F.E., Jacques N.A., Hunter N. (2005) Journal of clinical microbiology, 43(2): 843-849.

[18] Tanzer J.M., Livingston J., Thompson A.M. (2001) Journal of dental caries, 65(10): 1028-1037.

[19] Robertson D., Smith A.J. (2009 Journal of medical microbiology; 58: 155-162.

[20] Kuramitsu H.K., He X., Lux R., Anderson M.H., Shi W. (2007) Microbiology and molecular biology reviews, 71(4): 653670.

[21] Villedieu A., Diaz-Torres M.L., Hunt N., McNab R., Spratt D.A., Wilson M., Mullany (2003) Antimicrobial agents and chemotherapy;47(3): 878-882.

[22] Sakamoto M., Takeuchi Y., Umeda M., Ishikawa I., Benno Y. (2003) Journal of medical microbiology; 52: 79-89. 
Table 1- Colony characteristics of isolates

\begin{tabular}{|l|l|l|l|l|l|}
\hline CHARACTER & D-5 & D-8 & D-9 & D-15 & D-16 \\
\hline SIZE & Small & Small & Small & Small & Large \\
\hline SHAPE & Round & Round & Round & Round & Round \\
\hline MARGIN & Even & Even & Even & Even & Even \\
\hline ELEVATION & Flat & Flat & Flat & Flat & Elevated \\
\hline TEXTURE & Smooth & Smooth & Rough & Smooth & Rough \\
\hline PIGMENTATION & Green & Green & Green & Green & No \\
\hline OPACITY & Opaque & Opaque & Opaque & Opaque & Opaque \\
\hline
\end{tabular}

Table 2 Gram's characteristics of isolates

\begin{tabular}{|l|l|l|l|l|l|}
\hline CHARACTER & D-5 & D-8 & D-9 & D-15 & D-16 \\
\hline SIZE & Small & Small & Small & Small & Large \\
\hline SHAPE & Rod & Rod & Rod & Rod & Rod \\
\hline ARRANGEMENT & Single & Single & Chain & Single & Single \\
\hline $\begin{array}{l}\text { GRAM'S } \\
\text { NATURE }\end{array}$ & Negative & Negative & Negative & Negative & Positive \\
\hline
\end{tabular}

Table 3- Identification of the organisms by FAME analysis

\begin{tabular}{|l|l|l|}
\hline \multicolumn{1}{|c|}{ SAMPLE } & \multicolumn{1}{|c|}{ NAME OF ORGANISMS } & $\begin{array}{c}\text { NUMBER } \\
\text { OF } \\
\text { ISOLATES }\end{array}$ \\
\hline D-5, D-8, D-9, D-15 & Pseudomonas aeruginosa & 4 \\
\hline D-16 & Bacillus subtilis & 1 \\
\hline
\end{tabular}

Table 4- MIC determination of isolates

\begin{tabular}{|c|c|c|}
\hline SAMPLE & ORGANISM & $\mathrm{MIC}$ \\
\hline $\mathrm{D}-5$ & Pseudomonas aeruginosa & $16.0 \mathrm{mg} / \mathrm{mL}$ \\
\hline $\mathrm{D}-8$ & Pseudomonas aeruginosa & $15.5 \mathrm{mg} / \mathrm{mL}$ \\
\hline $\mathrm{D}-9$ & Pseudomonas aeruginosa & $14.0 \mathrm{mg} / \mathrm{mL}$ \\
\hline D-15 & Pseudomonas aeruginosa & $16.0 \mathrm{mg} / \mathrm{mL}$ \\
\hline D-16 & Bacillus subtilis & $16.0 \mathrm{mg} / \mathrm{mL}$ \\
\hline
\end{tabular}

Table 5- Quantity of extracted DNA

\begin{tabular}{|c|c|c|c|c|c|}
\hline SAMPLE & ORGANISM & A260 & A280 & A260/A280 & $\begin{array}{c}\text { CONCENTRATION } \\
\text { OF DNA (mg/mL) }\end{array}$ \\
\hline D-5 & P.aeruginosa & 0.322 & 0.331 & 0.97 & 1.61 \\
\hline D-8 & P.aeruginosa & 0.369 & 0.376 & 0.98 & 1.845 \\
\hline D-9 & P.aeruginosa & 0.387 & 0.394 & 0.98 & 1.935 \\
\hline D-15 & P.aeruginosa & 0.423 & 0.43 & 0.98 & 2.115 \\
\hline D-16 & B.subtilis & 0.344 & 0.353 & 0.97 & 1.72 \\
\hline
\end{tabular}




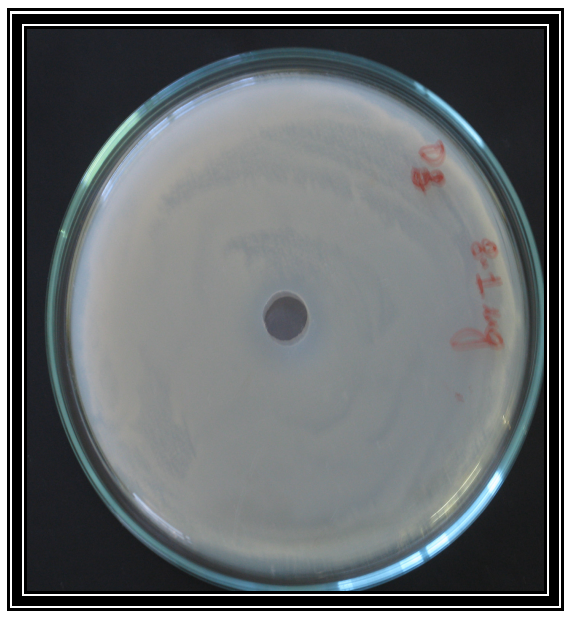

FIG.2- Plate is showing growth of tetracycline resistant organism, In the above figure we can observe there is no zone of inhibition near the cup having tetracycline. Indicating the organism is tetracycline resistant.

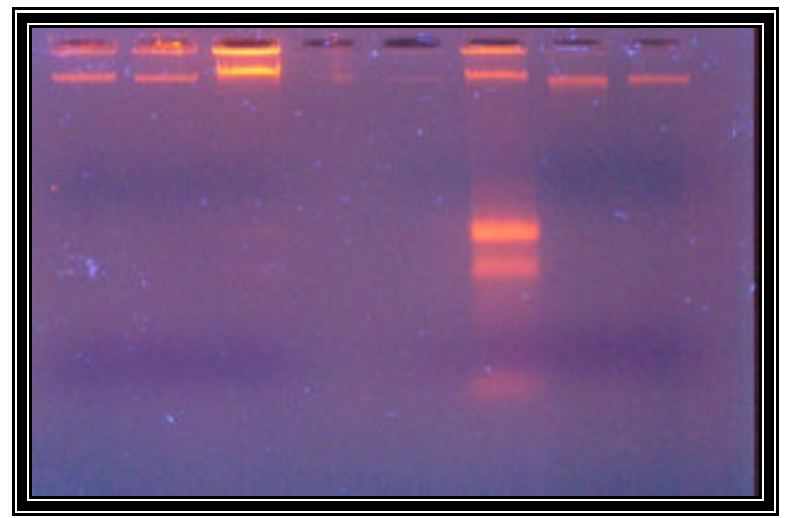

FIG.3- Electrophoresis of extracted genomic DNA

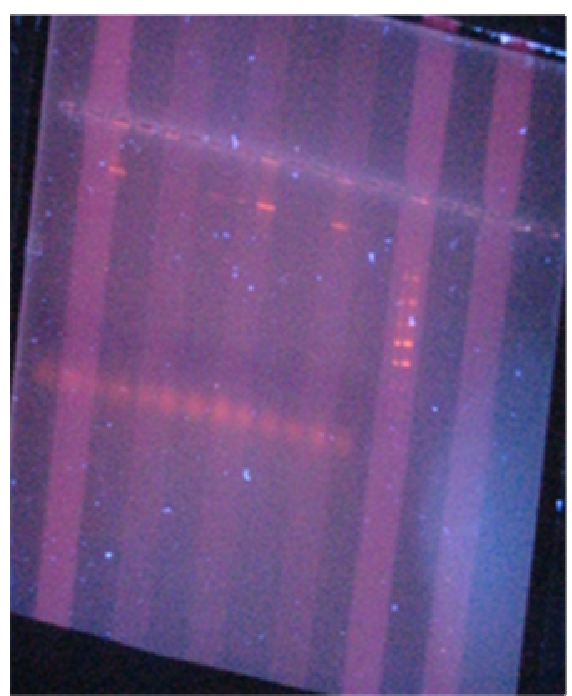

FIG.4- PCR amplification of tetK gene, and figure indicates the amplification of tetK gene in all the samples. 


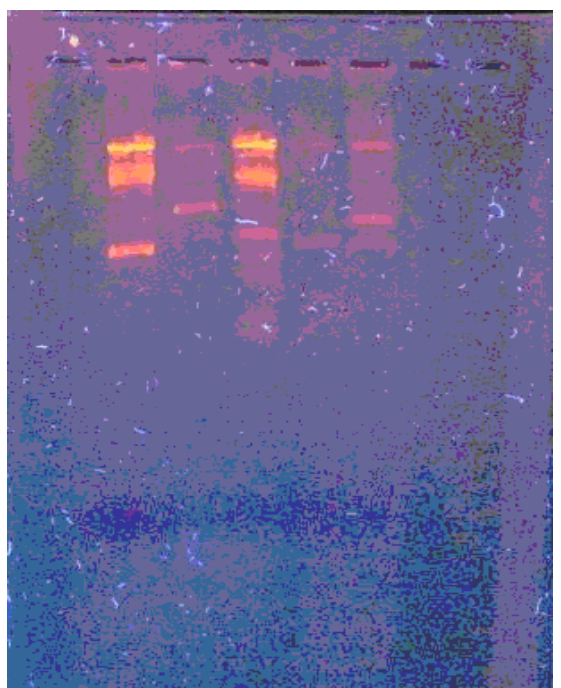

FIG.5- RFLP results using Hindlll restriction endonuclease

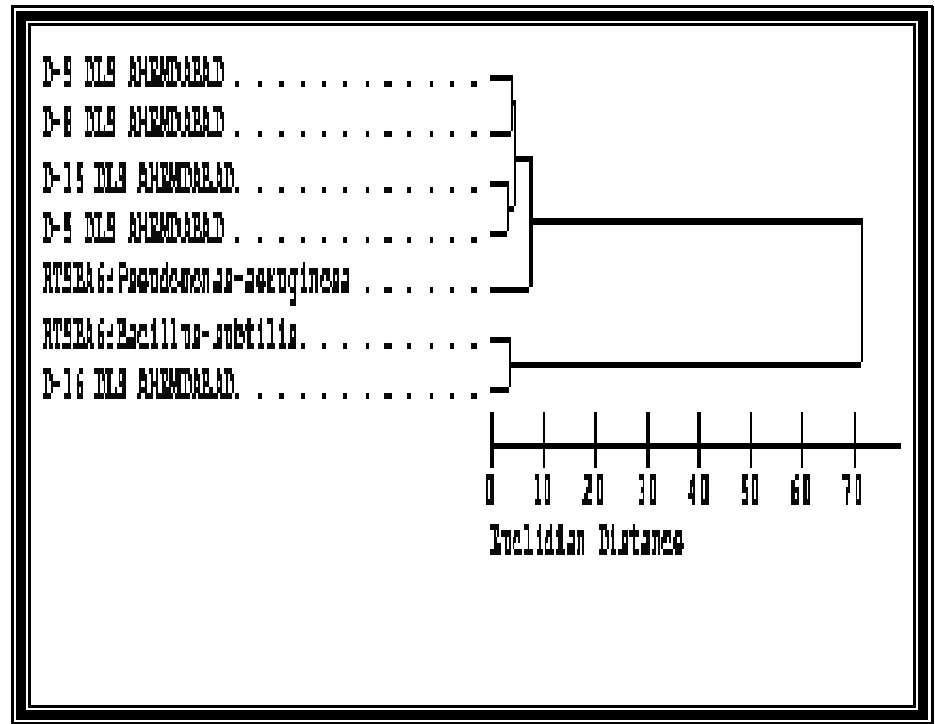

FIG. 6- Dendrogram showing phylogenetic relationship 